\title{
Family caregivers' role implementation at different stages of dementia
}

This article was published in the following Dove Press journal:

Clinical Interventions in Aging

5 January 2015

Number of times this article has been viewed

\author{
Huei-Ling Huang' \\ Yea-Ing L Shyu ${ }^{2,3}$ \\ Min-Chi Chen ${ }^{4}$ \\ Chin-Chang Huang 5,6 \\ Hung-Chou Kuo $0^{5,6}$ \\ Sien-Tsong Chen ${ }^{5,6}$ \\ Wen-Chuin $\mathrm{Hsu}^{6,7}$ \\ 'Department of Gerontological \\ Care and Management, Chang Gung \\ University of Science and Technology, \\ Taoyuan, Taiwan; ${ }^{2}$ School of Nursing, \\ College of Medicine, Chang Gung \\ University, Taoyuan, Taiwan; ${ }^{3}$ Healthy \\ Aging Research Center, Chang \\ Gung University, Taoyuan, Taiwan; \\ ${ }^{4}$ Department of Public Health and \\ Biostatistics Consulting Center, Chang \\ Gung University, Taoyuan, Taiwan; \\ ${ }^{5}$ Department of Neurology, Chang \\ Gung Memorial Hospital, Taoyuan, \\ Taiwan; ${ }^{6}$ School of Medicine, Chang \\ Gung University, Taoyuan, Taiwan; \\ ${ }^{7}$ Chang Gung Dementia Center, \\ Taoyuan, Taiwan
}

Correspondence: Yea-Ing L Shyu

School of Nursing, College of Medicine,

Chang Gung University, 259 Wen-Hwa

Ist Road, Kwei-Shan, Taoyuan 33302,

Taiwan

Tel +886321 I 8800 ext 5275

Fax +886 32118400

Email yeaing@mail.cgu.edu.tw
Purpose: The purpose of this study was to explore family caregivers' role-implementation experiences at different stages of dementia.

Patients and methods: For this cross-sectional, exploratory study, 176 dyads of family caregivers and their community-dwelling elderly relatives with dementia were recruited from the neurological clinics of a medical center in Taiwan. The Family Caregiving Inventory was used to assess family caregivers for caregiving activities, role strain, role preparation, and help from others at different stages of care receivers' dementia.

Results: Family caregivers' caregiving activities were related to patients' stages of dementia. For patients with mild dementia, caregivers provided more assistance in transportation and housekeeping. In addition to these two activities, family caregivers of patients with moderate dementia provided more assistance with mobility and protection. For patients with severe dementia, family caregivers provided more assistance with personal care, mobility and protection, transportation, and housekeeping. Overall, family caregivers reported having some preparation to provide care; the most difficult caregiving activity was identified as managing behavioral problems.

Conclusion: This study's results provide a knowledge base for designing dementia stagespecific interventions in clinical practice and developing community-based, long-term care systems for families of patients with dementia.

Keywords: behavioral problem, illness trajectory, role strain, caregiving activity, preparedness

\section{Introduction}

As the number of persons with dementia increases worldwide, along with the costs of their care, the importance of family caregiving will increase. The usual course of dementia is from 3 to over 9 years, with dementia symptoms characterized by changes at different stages. ${ }^{1-3}$ For example, instrumental self-care deficits begin early in dementia, basic self-care deficits increase as dementia advances, and many distressing behavioral symptoms decrease in late dementia. ${ }^{4}$ Thus, family caregivers' needs and how they implement their roles might change during the care receiver's illness trajectory.

Over the illness trajectory, the affected person, his/her family, and health professionals must combine their efforts to determine the eventual outcome, manage any symptoms, and handle illness-associated disabilities. ${ }^{5}$ In terms of the illness trajectory of dementia, its stages and severity are important to understand as factors influencing the coping and well-being of family caregivers. ${ }^{4,6}$ Indeed, family caregivers of patients with dementia were found to have a very time-consuming decision-making process, especially during the phase of exploring options after diagnosis, and their acceptance of the disease was very important in decreasing the patient's anxiety and resistance to care. ${ }^{7}$ Such family caregivers were also found to have high levels of burden associated 
with patients' low cognitive levels, behavioral problems, and nutritional problems. ${ }^{8}$ However, few studies have described and compared caregiving experiences at different stages of the dementia illness trajectory. In particular, no studies have focused on Chinese or Asian family caregivers.

During the illness trajectory, the interpretation and management of disease are influenced by the patient's and family's culture. ${ }^{9}$ Taiwan differs substantially from Western countries not only in ethnicity, but also in health care systems, clinical practice, culture, and social organization. For example, $66.5 \%$ of Taiwanese elders live with their children, ${ }^{10}$ whereas only one-fifth and one-quarter of the elderly live with an adult child in the United States and Europe, ${ }^{11}$ respectively. Studies on caregiving experiences conducted in Western countries are not likely to explain caregiving phenomena in Taiwan. For instance, family caregivers' commitment to care in other countries may be influenced by different sociocultural factors than in Taiwan and other Asian countries, where the family is the first line of support for elderly persons with dementia due to the cultural value of filial responsibility. Adult children are expected to take on the responsibilities of caring for their aging parents. ${ }^{12}$ Indeed, these adult child caregivers were found to care for their parents with dementia an average of 43 months and spent on average 13.45 hours per day caregiving. ${ }^{13}$ Under the current national health insurance reimbursement system in Taiwan, home services are not sufficient to support the caregiving tasks of family caregivers of the elderly with dementia. ${ }^{14}$ Thus, many caregivers $(34.9 \%)$ hire care aides, who are mostly foreign. ${ }^{13}$ Family caregivers not only have to take direct care of their older relative with dementia, but also supervise the care activities of foreign aides. Thus, caregiving phenomena in Taiwan might differ from those in other countries and need to be further explored.

A perspective on how caregivers actually carry out their caregiving role is provided by the interactionist approach to role theory, which proposes that the caregiver role is created by caregiver-care receiver interactions and caregiver-care receiver dyad interactions with others. ${ }^{15,16}$ In the interactionist approach to role theory, the concept of role implementation is emphasized, ie, the tasks and behaviors comprising the role, how role implementation is influenced by interactions between role partners, and role preparation. ${ }^{16}$ In caregiving, role implementation is therefore defined by caregiving activities (caregiving demand), mutuality between caregivers and care receivers, and preparedness for caregiving. These role implementation variables were found to predict multiple caregiving-specific and generic outcomes, ${ }^{17,18}$ giving health care professionals new insights about how to assist family caregivers to effectively implement their caregiver role. ${ }^{15,19,20}$ Although family caregiving for patients with dementia has been well studied, few studies have focused on implementation of the caregiving role during the stages of dementia. Therefore, the purpose of this study was to explore family caregivers' role-implementation experiences at different stages of dementia, including caregiver experiences of caregiving activities, role strain, preparedness, and help from others. We hypothesized that caregiving activities, role strain, preparedness, and help from others would change at different stages of dementia. We further hypothesized that caregiver activities, role strain, and help from others would increase, and that preparedness would decrease, as the stages of dementia progressed. Understanding the role-implementation experiences of caregivers during the dementia illness trajectory can provide a basis for developing specific interventions for families of patients at different stages of dementia.

\section{Materials and methods Study design}

A cross-sectional, exploratory design was used to explore the caregiving activities, role strain, role preparation, and help from others of family caregivers for patients at different stages of dementia.

\section{Study setting and participants}

A convenience sample of family caregivers and patients with dementia was recruited from the neurological wards of a 3,800-bed medical center and a local hospital in Northern Taiwan. Patients with dementia were included if they met these criteria: 1) $\geq 65$ years, 2) diagnosed with dementia by a neurologist or psychiatrist, and 3) cared for in a home setting. Care receivers' characteristics are presented in Table 1. Family caregivers were included if they met these criteria: $1) \geq 18$ years and 2) having primary responsibility for the care of the elder with dementia. Overall, the refusal rate was $15 \%$, primarily due to not having time to give informed consent during the clinic visit or not being interested in participating. Of 250 family caregivers enrolled in the study, 176 (70.4\%) completed the questionnaires. Family caregivers' characteristics are presented in Table 2.

\section{Procedures}

The study was approved by the Institutional Review Board of Chang Gung University, Taoyuan, Taiwan and appropriate review boards at the medical center (no 94-891). Families who met the inclusion criteria were identified by clinic neurologists, 


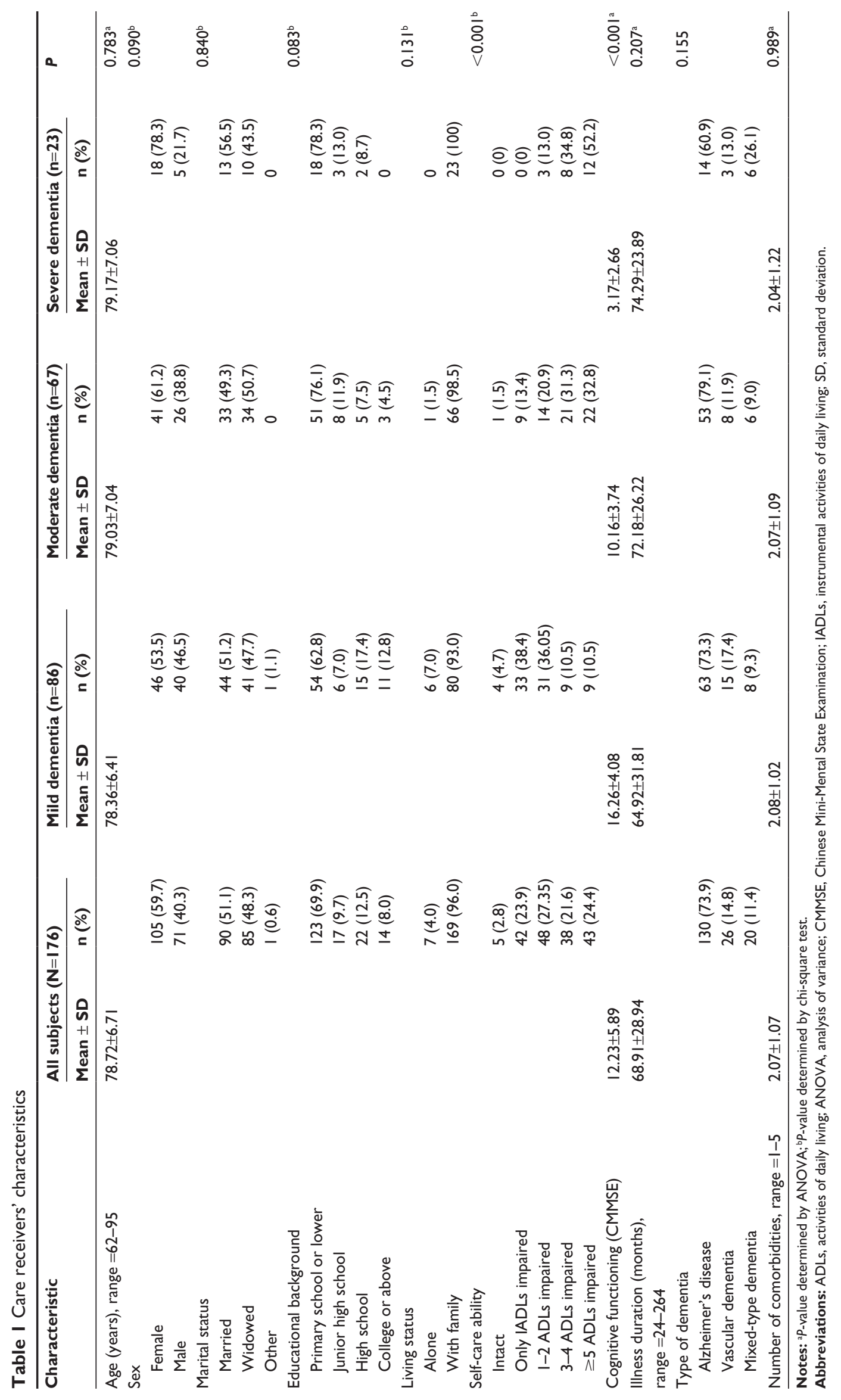




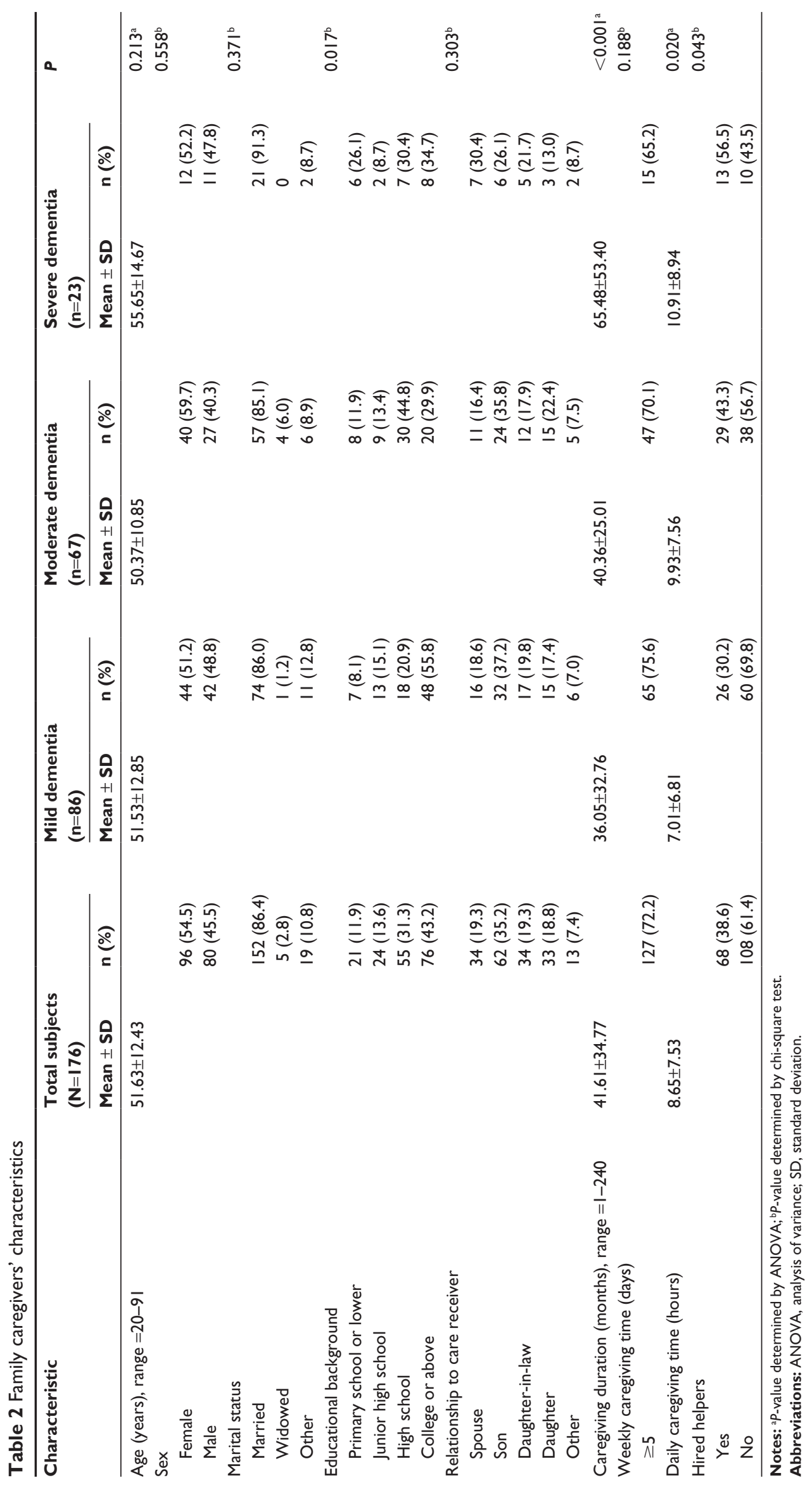


who obtained family members' permission for an investigator to contact them. Families who expressed an interest were contacted by research assistants who further explained the study and gave them a questionnaire packet to complete at home and return by mail. Research assistants then contacted participants by telephone to answer any questions they might have and to remind them to send the questionnaire back.

\section{Measures}

\section{Clinical Dementia Rating (CDR) scale}

The severity of dementia was determined by a neurologist using the CDR scale, ${ }^{21}$ which was routinely used to collect clinical data. The CDR scale uses a semi-structured interview with both the patient and a reliable informant to assess performance of cognitive functions in six domains: memory, orientation, judgment and problem solving, community affairs, home and hobbies, and personal care. Each domain is rated for level of impairment: none (0), questionable (0.5), mild (1), moderate (2), and severe (3). The transcultural feasibility, reliability, and validity of the CDR have been established in a Chinese population, ${ }^{22}$ and the CDR has been used in dementia studies in Taiwan. ${ }^{23,24}$

\section{Caregiving activities}

Caregiving activities, ie, what and how much the family caregiver has to do to assist the care receiver, were measured using the Caregiving Activities Scale of the Family Caregiving Inventory (FCI). ${ }^{19,25,26}$ This 87 -item scale measures tasks related to personal care (15 items), mobility and protection (seven items), illness-related care (19 items), banking and legal issues (four items), transportation (five items), housekeeping (three items), emotional support (12 items), managing symptoms of dementia (13 items), and arranging care (six items). For each item, the score is either 0 (no) or 1 (yes). The score for each subscale is calculated by summing the item scores and dividing by the number of caregiving tasks the family caregiver indicated that he/she needs to perform. For this study, the FCI was translated and back-translated to establish the validity of the Chinese-version FCI. Reliability estimates ranged between 0.80 and $0.90{ }^{19,25,26}$ In this study, the internal consistency reliability of the Caregiving Activities Scale, assessed using the Kuder-Richardson Formula 20, ranged from 0.60 to 0.90 .

\section{Role strain}

Role strain, the felt difficulty in fulfilling the role obligations of family caregiver, ${ }^{19}$ was measured by the 87 -item Role Strain Scale of the FCI as the degree of difficulty perceived by family caregivers in administering different types of family caregiving tasks. For each item, the score ranges from 0 (easy) to 4 (very difficult). The reliability of the Role Strain Scale of the FCI has been reported to exceed 0.70 (usually 0.80 to 0.90$).{ }^{19,25,26}$ Cronbach's alpha for the Role Strain Scale of the FCI in this study ranged from 0.70 to 0.90 .

\section{Preparedness}

Preparedness, which refers to a caregiver's self-assessment of his/her adequacy for providing care, was measured by self-report on an eight-item Preparedness Scale that rates how well caregivers think they are prepared for seven domains of caregiving. ${ }^{19,25} \mathrm{~A}$ final question asks caregivers to give an overall rating of how well prepared they are to care for the care receiver. Scores can range from 0 to 32, with 0 representing least prepared and 32 representing most prepared. Cronbach's alphas ranged from 0.86 to 0.92 in studies on family caregiving of frail elders in the US. ${ }^{19,27-29}$ The Preparedness Scale was translated and back-translated in this study to establish the validity of the Chinese version, and Cronbach's alpha was 0.92 .

\section{Amount of help from others}

Amount of help from others, ie, what and how much other people help family caregivers in delivering caregiving activities, was measured using the Help from Others scale in the FCI. ${ }^{19,25,26}$ This three-item scale measures amount of help from relatives, hired aides, and friends and neighbors. For each item, response options are none at all (0), a little (1), some (2), quite a bit (3) and a great deal (4). The amount of help from others is calculated by summing the scores of the three items. Scores can range from 0 to 12 , with 0 representing no help from others and 12 representing a great deal of help from others. This scale was translated and back-translated in this study to establish the validity of the Chinese version, and Cronbach's alpha was 0.50 . The low internal reliability could have resulted from the small number of questions..$^{30,31}$

\section{Characteristics of elderly persons with dementia}

Self-care ability of elderly persons with dementia was measured by caregivers' reports on the Chinese Barthel Index, which assesses performance of activities of daily living (ADLs), ${ }^{32,33}$ and the Instrumental Activities of Daily Living Index. ${ }^{34}$ Elderly persons were categorized as independent; only instrumental ADLs impaired; one to two ADLs impaired; three to four ADLs impaired; or five or more ADLs impaired. ${ }^{35,36}$ The number of comorbidities was collected from patients' medical charts. Cognitive functioning was 
measured by the Chinese version of the Mini-Mental State Examination (MMSE). ${ }^{37}$

\section{Data analysis}

Data were analyzed using SPSS 19.0 software. Statistical significance was determined at $P<0.05$. Sample characteristics were analyzed by descriptive statistics. Among-group differences in continuous-variable characteristics were examined by one-way analysis of variance (ANOVA). Among-group differences in categorical characteristics were examined by chisquare tests. Differences in caregiving activities, role strain, preparedness, and amount of help from others were examined by analysis of covariance (ANCOVA) among different dementia severity groups (mild, moderate, or severe dementia) after controlling for caregivers' years of education. For outcome variables that were significant in ANCOVA, group differences were further examined by Scheffé post hoc tests. Group differences in single items related to preparedness and amount of help from others were further examined by sequential application of the Kruskal-Wallis and Mann-Whitney $U$-tests.

\section{Results}

\section{Caregiving activities}

In terms of caregiving activities (Figure 1, Table S1), family caregivers of patients with mild dementia provided more assistance with transportation than with other caregiving activities. In addition to transportation, family caregivers of patients with moderate dementia provided more assistance with mobility and protection than with other activities. For family caregivers of patients with severe dementia, more assistance was provided for personal care, mobility and protection, transportation, and housekeeping than for other caregiving activities.

Comparison of amount of care activities performed by caregivers at different stages of dementia (CDR rating), after controlling for family caregivers' years of education, showed that caregivers of patients with moderate and severe dementia provided significantly more overall care activities $(F=10.21$, $P<0.001)$, personal care $(F=35.87, P<0.001)$, and mobility and protection $(F=8.52, P<0.001)$ than caregivers of patients with mild dementia. At the same time, after controlling for family caregivers' years of education, caregivers of patients with moderate dementia provided significantly more illness-related care $(F=4.25, P<0.05)$, housekeeping $(F=3.85, P<0.05)$, and care activities related to symptoms of dementia $(F=3.72$, $P<0.05)$ than caregivers of patients with mild dementia.

\section{Role strain}

Family caregivers' average role strain from doing nine types of care activities for persons with mild, moderate, or severe dementia is shown in Figure 2 and Table S2. Caregivers' difficulty associated with most types of caregiving activities for patients with mild dementia ranged from easy (mean [M] $=0.39$, standard deviation $[\mathrm{SD}]=0.49)$ to not too hard $(\mathrm{M}$ $=0.88, \mathrm{SD}=0.67)$, except for activities related to managing symptoms of dementia ( $\mathrm{M}=1.23, \mathrm{SD}=0.76)$, which ranged from not too difficult to somewhat difficult. Most types of caregiving activities for patients with moderate dementia

Type of care activity

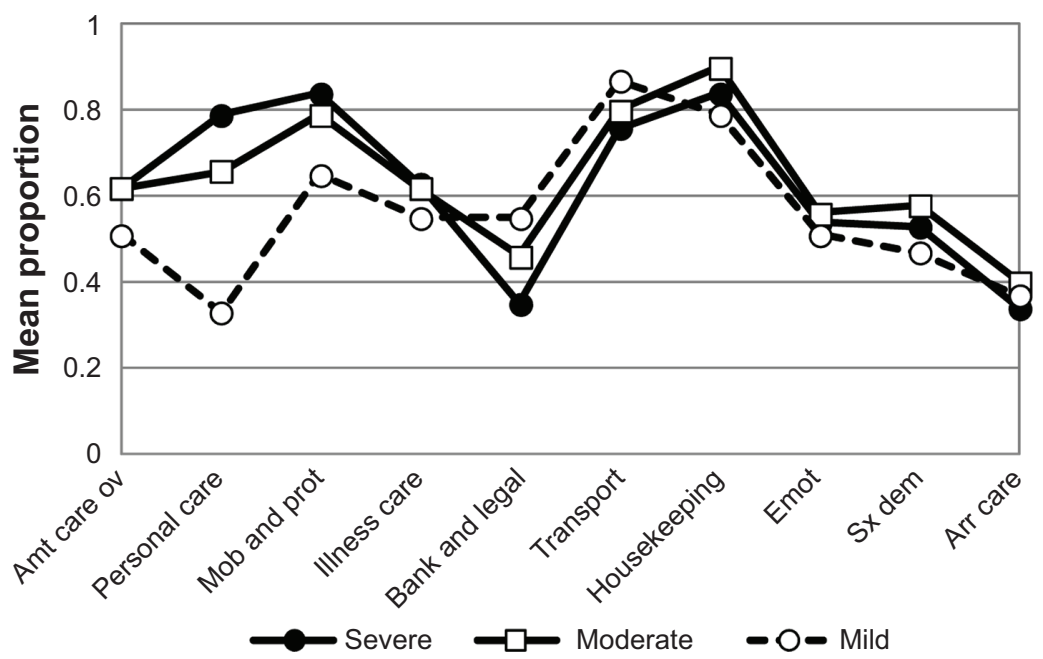

Figure I Average proportion of caregivers' types of care activities for care receivers with mild, moderate, or severe dementia.

Abbreviations: Amt care ov, overall amount of care activities; Mob and prot, mobility and protection; Illness care, illness-related care; Bank and legal, managing banking and legal issues; Emot, emotional support; Sx dem, managing symptoms of dementia; Arr care, arranging care. 


\section{Type of care activity}

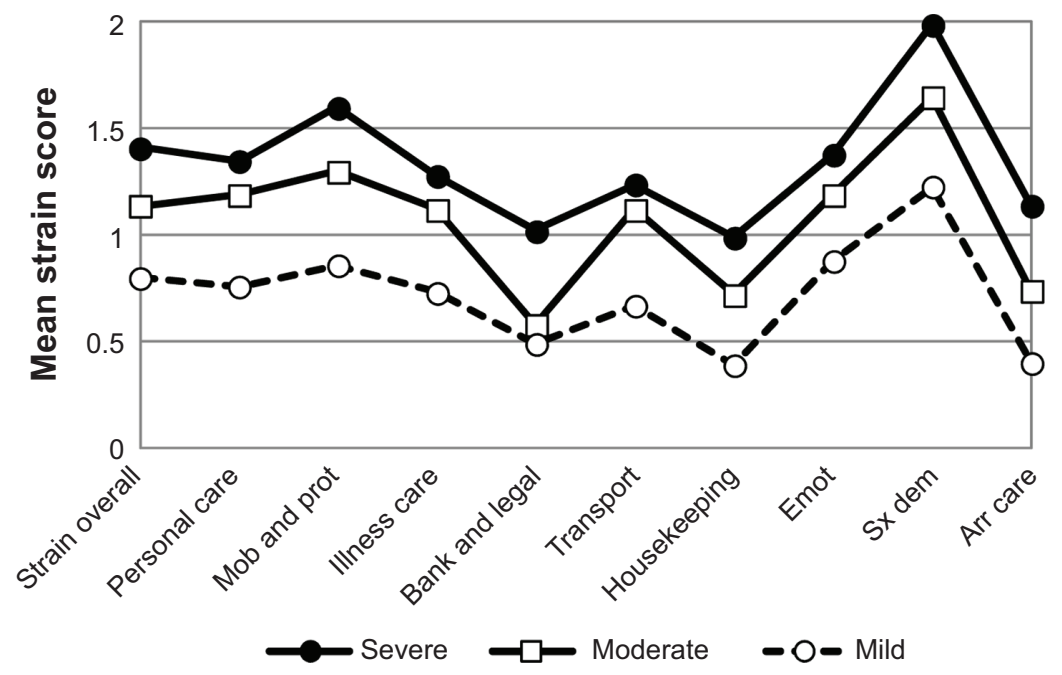

Figure 2 Family caregivers' average role strain from nine types of care activities for persons with mild, moderate, or severe dementia.

Abbreviations: Strain overall, role strain for overall amount of care activities; Mob and prot, mobility and protection; Illness care, illness-related care; Bank and legal, managing banking and legal issues; Emot, emotional support; Sx dem, managing symptoms of dementia; Arr care, arranging care.

ranged from not too difficult $(\mathrm{M}=1.19, \mathrm{SD}=0.85)$ to somewhat difficult $(\mathrm{M}=1.65, \mathrm{SD}=0.96)$, except for helping with banking and legal issues $(\mathrm{M}=0.58, \mathrm{SD}=0.73)$ and housekeeping $(\mathrm{M}=0.72, \mathrm{SD}=0.74)$, which ranged between easy and not too difficult. For caregivers of patients with severe dementia, all types of caregiving activities ranged from not too difficult ( $\mathrm{M}=0.99, \mathrm{SD}=0.99$ ) to somewhat difficult ( $\mathrm{M}$ $=1.99, \mathrm{SD}=1.02$ ). The most difficult type of caregiving activity reported for patients at all three stages of dementia (severity level) was managing symptoms of dementia.

Comparison among patients at different stages of dementia showed that caregivers of patients with moderate and severe dementia experienced more role strain related to overall amount of care activities $(F=12.69, P<0.001)$ and more role strain related to all types of caregiving activities, except for role strain related to managing banking and legal issues and arranging care, than caregivers of patients with mild dementia. For managing banking and legal issues, more role strain was reported by caregivers of patients with severe dementia than by caregivers of patients with mild and moderate dementia $(F=3.43, P<0.05)$. For arranging care, more role strain was also reported by caregivers of patients with severe dementia than by caregivers of patients with moderate dementia $(F=14.06, P<0.001)$.

\section{Preparedness}

Overall, family caregivers reported being somewhat prepared for the caregiver role (for caregivers of patients with mild dementia, $\mathrm{M}=2.10, \mathrm{SD}=0.70$; for caregivers of the moderate dementia group, $\mathrm{M}=2.05, \mathrm{SD}=0.80$; and for caregivers of the severe dementia group, $\mathrm{M}=1.77, \mathrm{SD}=1.02$ ). In terms of items measuring preparedness, the overall sample felt less prepared to make care activities pleasant for both caregiver and patient $(\mathrm{M}=1.90, \mathrm{SD}=1.0)$ and to get help and information from health care systems $(\mathrm{M}=1.90, \mathrm{SD}=0.97)$ than for the other items ( $M=2.01$ to 2.14). Although family caregivers of patients with severe dementia felt less prepared than caregivers of patients with mild and moderate dementia, preparedness did not differ significantly among the three groups.

\section{Help from others}

In terms of overall help, family caregivers received a little help from others $(\mathrm{M}=3.19, \mathrm{SD}=2.59)$. Caregivers of patients with moderate and severe dementia received more overall help $(\mathrm{M}=3.46, \mathrm{SD}=2.75$ and $\mathrm{M}=4.04, \mathrm{SD}=2.77$, respectively) from others $(F=3.88, P<0.05)$ than caregivers of patients with mild dementia $(\mathrm{M}=2.76, \mathrm{SD}=2.35)$. In particular, caregivers of patients with severe dementia received more help from people they paid $(\mathrm{M}=2.22$, $\mathrm{SD}=1.59)$ than caregivers of patients with mild dementia ( $\mathrm{SD}=1.00, \mathrm{SD}=1.51$ ). The three groups of caregivers did not differ significantly in amount of help from relatives and friends/neighbors.

\section{Discussion}

This study is the first to characterize the role-implementation experiences at different stages of dementia in a Taiwanese sample of family caregivers. We found that caregivers' caregiving activities were related to patients' stages of 
dementia. Caregivers of patients with mild dementia provided more assistance in transportation than caregivers of patients with moderate and severe dementia. This difference might be due to persons with more advanced dementia being more difficult to engage in outside activities, easily resulting in frustrating experiences and shame for caregivers. ${ }^{38,39}$ Caregivers provided more assistance with housekeeping and mobility and protection for patients with moderate dementia and more assistance with personal care for patients with severe dementia than caregivers of patients with mild and moderate dementia, respectively. These differences might be due to increasing impairment in instrumental ADLs and ADLs with more advanced stages of dementia, as shown in Table 1. This possibility is supported by prior reports that instrumental self-care deficits begin early in dementia and basic self-care deficits increase with dementia severity. ${ }^{4,40}$ Our results also echo a report that the amount and associated economic cost of informal care to patients with dementia increased dramatically as their cognitive impairment progressed. ${ }^{41}$ Family caregivers of patients with moderate and severe dementia experienced more difficulty associated with most types of caregiving activities overall than caregivers of patients with mild dementia. Perceived difficulty associated with the caregiving role in terms of the care receiver's dementia stage has not previously been studied, but one study found that, when spousal caregivers of the elderly transitioned to heavy caregiving over 5 years, they had more depressive symptoms and poorer perceived health. ${ }^{42}$ In particular, our study found that managing symptoms of dementia was the most difficult caregiving activity at all stages of dementia. This result is supported by a review of the dementia caregiving literature ${ }^{32}$ that shows that family caregivers' mental and physical morbidity was associated with patients' problem behaviors. Similarly, family caregiver burden was associated with dementia-related symptoms, an association that became stronger over time, ${ }^{6}$ and was inversely associated with low MMSE scores and behavioral problems. ${ }^{8}$

The family caregivers in this study reported being somewhat prepared for their role, which is less prepared than reported by US family caregivers of elderly persons after hospital discharge ${ }^{19}$ and patients with cancer. ${ }^{16}$ Whether these differences are due to taking care of patients with different conditions or to cultural differences needs to be further explored. Assessing family caregivers' acceptance of and preparation for the caregiver role is important, since acceptance is critical in decreasing anxiety and resistance to care. ${ }^{7}$ It is worth noting that family caregivers in our study reported feeling only somewhat prepared to provide care regardless of patients' dementia severity, especially in making care activities pleasant for both caregiver and patient as well as in getting help and information from health care systems.

Most of the help received by family caregivers was from hired helpers, and the amount of help increased as the severity of dementia increased, from one-third of family caregivers of patients with mild dementia to over one-half of the family caregivers of patients with severe dementia. These results are consistent with previous findings that around $30 \%$ of Taiwanese family caregivers of patients with dementia had paid assistance. ${ }^{43,13}$ Despite the difficulties for Taiwanese families in caring for their disabled older family members at home, due to smaller families and the influence of industrialization, ${ }^{44}$ most family caregivers of patients with dementia still believed that home care is the best method of care. ${ }^{45}$ In the present study, 66 (37.5\%) family caregivers were assisted by a foreign worker, and only two (1.1\%) had assistance from a Taiwanese worker. These percentages are lower than those in a previous report, which stated that $18.7 \%$ to $60 \%$ of US family caregivers of patients with dementia hired foreign workers. ${ }^{46}$ Hiring paid helpers, especially female foreign workers from Southeast Asian countries, is one way for caregivers to meet the care needs of disabled family members in Taiwan. ${ }^{44}$

\section{Conclusion}

Our study findings have several implications for clinical practice and policy making. First, different services and interventions need to be designed for families of patients with dementia according to their specific needs at different stages of dementia. For example, community services should be available to help patients with mild dementia with transportation and housekeeping. For patients with moderate to severe dementia, services and devices are needed to help family caregivers protect patients and assist with mobility, such as in-home helpers, night helpers, and safety-monitoring devices. For patients with severe dementia, more intensive help should be considered to provide personal care.

Second, support and consultation programs need to be provided for family caregivers of patients with dementia at all stages, since these caregivers are all less than optimally prepared regardless of dementia stage. In particular, consultations should address how to make care activities pleasant for both caregivers and patients, as well as how to get help and information from health care systems. Last, attention needs to be paid to the high percentage of hired foreign helpers. The language and knowledge/skills of foreign helpers with regard to taking care of patients with dementia need to be 
assessed, with training offered, if necessary, so that quality care can be provided to elderly persons with dementia.

The generalizability of our study results are somewhat limited by using a convenience sample. The impact of this sampling, however, may have been minimized by the similarity between the profiles of our sample and the sample from an earlier study of family caregivers of patients with dementia in Taiwan. ${ }^{47-49}$ This similarity adds to our study's credibility and improves the generalizability of the results. A second limitation is that we did not measure the exact time spent on each caregiving activity, preventing a precise estimation of the amount of caregiving activities. A third limitation was the limited range of dementia stages. Pre-dementia, very severe, and terminal stages of dementia were not assessed, limiting understanding of the role-implementation experiences of family caregivers taking care of elderly persons with dementia at these stages. To illuminate these phenomena, future studies should use random sampling to represent all families of patients with dementia at all stages and to obtain a more comprehensive assessment of care activities.

Despite its limitations, this study expands the results of previous studies on family caregivers of elderly persons with dementia by describing caregivers' role-implementation experiences at different stages of dementia in Taiwan. This information can provide a knowledge base for developing community-based, long-term care services to support families of elderly persons with dementia and serves as a guide for developing interventions and future studies. As the population of Asian elders is rapidly growing in Western countries, this study's results may be applicable to other countries wherein health care providers have to take into account the needs of Chinese/Taiwanese immigrants.

\section{Acknowledgments}

We would like to thank the nurses and doctors in the neurological clinics of Chang Gung Memorial Hospital for referring participants in this study. We would also like to thank Professors Patricia G Archbold and Barbara J Stewart for their assistance in developing the instruments, designing the study, and providing insight during the research process. A special thanks to the people with dementia and their family caregivers for participating in this study. This study was supported by the National Science Council, Taiwan (NSC 93-2314-B-182-068 and NSC95-2420-H-182-002-KF); Chang Gung Medical Foundation (CMRPD1B0332); and Ministry of Education, Republic of China (Taiwan) (EMRPD1D0261).

\section{Author contributions}

Huei-Ling Huang was responsible for study concept and design, instrument development, data entry and analysis, interpretation of data, and preparation of the manuscript. Yea-Ing L Shyu was responsible for study concept and design, interpretation of data, and preparation of the manuscript. MinChi Chen was involved in analysis and interpretation of the data analysis and preparation of the manuscript. Chin-Chang Huang, Hung-Chou Kuo, Sien-Tsong Chen, and Wen-Chuin Hsu were involved in recruitment of subjects, data collection, and preparation of the manuscript.

\section{Disclosure}

The authors report no conflicts of interest in this work.

\section{References}

1. Cohen D, Kennedy G, Eisdorfer C. Phases of change in the patient with Alzheimer's dementia: a conceptual dimension for defining health care management. J Am Geriatr Soc. 1984;32(1):11-15.

2. Buijssen H. The Simplicity of Dementia: A Guide for Family and Carers. London: Jessica Kingsley Publishers; 2005.

3. Wolfson C, Wolfson DB, Asgharian M, et al; Clinical Progression of Dementia Study Group. A reevaluation of the duration of survival after the onset of dementia. N Engl J Med. 2001;344(15):1111-1116.

4. Haley WE, Pardo KM. Relationship of severity of dementia to caregiving stressors. Psychol Aging. 1989;4(4):389-392.

5. Corbin JM, Strauss A. A nursing model for chronic illness management based upon the Trajectory Framework. Sch Inq Nurs Pract. 1991; 5(3):155-174.

6. Berger G, Bernhardt T, Weimer E, Peters J, Kratzsch T, Frolich L. Longitudinal study on the relationship between symptomatology of dementia and levels of subjective burden and depression among family caregivers in memory clinic patients. $J$ Geriatr Psychiatry Neurol. 2005;18(3):119-128.

7. Wolfs CA, de Vugt ME, Verkaaik M, et al. Rational decision-making about treatment and care in dementia: a contradiction in terms? Patient Educ Couns. 2012;87(1):43-48.

8. Andrieu S, Balardy L, Gilette-Guyonnet S, et al. [Burden experienced by informal caregivers assisting Alzheimer's patients in the REAL. FR.study]. Rev Med Interne. 2003;24 (Suppl 3):351s-359s. French.

9. Surbone A, Peccatori FA. Unmet needs of cancer survivors: supportive care's new challenge. Support Care Cancer. 2006;14(5):397-399.

10. Report of the senior citizen condition survey in 2009 [webpage on the Internet]. Taipei: Department of Statistics, Ministry of the Interior, Republic of China [updated March 12, 2011; cited October 29, 2013]. Available from: http://www.moi.gov.tw/stat/news_content. aspx?sn=5060. Accessed October 29, 2013.

11. Pezzin LE, Pollak RA, Schone BS. Efficiency in family bargaining: living arrangements and caregiving decisions of adult children and disabled elderly parents. CESifo Econ Stud. 2007;53:69-96.

12. Chan SW. Family caregiving in dementia: the Asian perspective of a global problem. Dement Geriatr Cogn Disord. 2010;30(6):469-478.

13. Huang HL, Kuo LM, Chen YS, et al. A home-based training program improves caregivers' skills and dementia patients' aggressive behaviors: a randomized controlled trial. Am J Geriatr Psychiatry. 2013;21(11): 1060-1070.

14. Shyu YI, Huang HL, Huang HL, Chen ST. Caregiving needs and service utilization for older people with dementia. In: Wu SC, editor. Proceedings of the Conference on Comprehensive Planning for the Coming of Aging Society in Taiwan; 2008 Apr 18-19; Taipei, Taiwan. Taipei: Ministry of Science and Technology; 2008:1-31. 
15. Schumacher KL. Family caregiver role acquisition: role-making through situated interaction. Sch Inq Nurs Pract. 1995;9(3):211-226; discussion 227-229.

16. Schumacher KL, Stewart BJ, Archbold PG, Caparro M, Mutale F, Agrawal S. Effects of caregiving demand, mutuality, and preparedness on family caregiver outcomes during cancer treatment. Oncol Nurs Forum. 2008;35(1):49-56.

17. Schumacher KL, Stewart BJ, Archbold PG. Mutuality and preparedness moderate the effects of caregiving demand on cancer family caregiver outcomes. Nurs Res. 2007;56(6):425-433.

18. Shyu YI, Yang CT, Huang CC, Kuo HC, Chen ST, Hsu WC. Influences of mutuality, preparedness, and balance on caregivers of patients with dementia. J Nurs Res. 2010;18(3):155-163.

19. Archbold PG, Stewart BJ, Greenlick MR, Harvath T. Mutuality and preparedness as predictors of caregiver role strain. Res Nurs Health. 1990;13(6):375-384.

20. Burr WR, Leigh GK, Day RD, Constantine J. Symbolic interaction and the family. In: Burr WR, Hill R, editors. Contemporary Theories about the Family: General Theories. New York, NY, USA: Free Press; 1979:42-111.

21. Hughes CP, Berg L, Danziger WL, Coben LA, Martin RL. A new clinical scale for the staging of dementia. Br J Psychiatry. 1982;140: 566-572.

22. Lim WS, Chin JJ, Lam CK, Lim PP, Sahadevan S. Clinical dementia rating: experience of a multi-racial Asian population. Alzheimer Dis Assoc Disord. 2005;19(3):135-142.

23. Liu CK, Lin RT, Howng SL, Ueng TS, Wang FM, Chang C. Types of dementia in Taiwan - a prospective study. Gaoxiong Yi Xue Ke Xue Za Zhi. 1992;8(6):290-298.

24. Liu L, Tinker A. Entry to nursing homes in Taiwan, Republic of China: the role and involvement of families. Qual Ageing. 2002;3:27-35.

25. Archbold PG, Stewart BJ, Greenlick MR, Harvath TA. The clinical assessment of mutuality and preparedness in family caregivers to frail older people. In: Funk SG, Tornquist EM, Champagne MT, Wiese RA, editors. Key Aspects of Elder Care. Managing Falls, Incontinence, and Cognitive Impairment. New York, NY, USA: Springer; 1992:328-339.

26. Stewart BJ, Archbold PG, Harvath TA, Nkongho NO. Role acquisition in family caregivers for older people who have been discharged from the hospital. In: Funk SG, Tornquist EM, Champagne MT, Wiese RA, editors. Key Aspects of Caring for the Chronically Ill: Hospital and Home. New York, NY, USA: Springer; 1993:219-231.

27. Archbold PG, Stewart BJ, Miller LL, et al. The PREP system of nursing interventions: a pilot test with families caring for older members. Preparedness (PR), enrichment (E) and predictability (P). Res Nurs Health. 1995;18(1):3-16.

28. Carter JH, Stewart BJ, Archbold PG, et al. Living with a person who has Parkinson's disease: the spouse's perspective by stage of disease. Parkinson's Study Group. Mov Disord. 1998;13(1):20-28.

29. Kirschling JM, Stewart BJ, Archbold PG. Family caregivers of posthospitalized older persons and persons receiving hospice: similarities and differences. Home Health Care Serv Q. 1994;14(4):117-140.

30. Nunnally JC, Bernstein IH. Psychometric Theory. Third Ed. New York, NY, USA: McGraw-Hill Higher; 1994.
31. Tavakol M, Dennick R. Making sense of Cronbach's alpha. Int J Med Educ. 2011;2:53-55.

32. Chen YJ, Dai YT, Yang CT. A Review and Proposal on Patient Classification in Long-Term Care System. Taipei: Department of Health, Republic of China; 1995.

33. Katz S, Ford AB, Moskowitz RW, Jackson BA, Jaffe MW. Studies of illness in the aged. The index of ADL: a standardized measure of biological and psychosocial function. JAMA. 1963;185:914-919.

34. Lawton MP, Brody EM. Assessment of older people. Self-monitoring and instrumental activities of daily living. Gerontologist. 1969;9: 179-186.

35. Kane RA, Kane RL. Long-Term Care: Principles, Programs, and Policies. New York, NY, USA: Springer; 1987.

36. Rosenbach ML. Access and satisfaction within the disabled Medicare population. Health Care Financ Rev. 1995;17(2):147-167.

37. Yip PK, Shyu YI, Liu SI. An epidemiological survey of dementia among elderly in urban district of Taipei. Acta Neurologica Sinica. 1992; 3:347-354.

38. Mukadam N, Cooper C, Livingston G. A systematic review of ethnicity and pathways to care in dementia. Int J Geriatr Psychiatry. 2011; 26:12-20

39. Lee SM, Lin X, Haralambous B, et al. Factors impacting on early detection of dementia in older people of Asian background in primary healthcare. Asia Pac Psychiatry. 2011;3:120-127.

40. Marshall GA, Amariglio RE, Sperling RA, Rentz DM. Activities of daily living: where do they fit in the diagnosis of Alzheimer's disease? Neurodegener Dis Manag. 2012;2(5):483-491.

41. Langa KM, Chernew ME, Kabeto MU, et al. National estimates of the quantity and cost of informal caregiving for the elderly with dementia. J Gen Intern Med. 2001;16:770-778.

42. Burton LC, Zdaniuk B, Schulz R, Jackson S, Hirsch C. Transitions in spousal caregiving. Gerontologist. 2003;43(2):230-241.

43. Huang CY, Musil CM, Zauszniewski JA, Wykle M. Effects of social support and coping of family caregivers of older adults with dementia in Taiwan. Int J Aging Hum Dev. 2006;63:1-25.

44. Chiou CJ, Chen IP, Wang HH. The health status of family caregivers in Taiwan: an analysis of gender differences. Int J Geriatr Psychiatry. 2005;20:821-826

45. Chang M, Wu SC, Chuang KY. The care needs of people in the community with cognitive impairment. Taiwan J Public Health. 2004; 23:181-187.

46. Chang BL, Brecht ML, Carter PA. Predictors of social support and caregiver outcomes. Women Health. 2001;33(1-2):39-61.

47. Chou KR, LaMontagne LL, Hepworth JT. Burden experienced by caregivers of relatives with dementia in Taiwan. Nurs Res. 1999;48: 206-214.

48. Fuh JL, Wang SJ. Assessing quality of life in Taiwanese patients with Alzheimer's disease. Int J Geriatr Psychiatry. 2006;21:103-107.

49. Huang HL, Shyu YI, Chen MC, Chen ST, Lin LC. A pilot study on a home-based caregiver training program for improving caregiver selfefficacy and decreasing the behavioral problems of elders with dementia in Taiwan. Int J Geriatr Psychiatry. 2003;18:337-345. 


\section{Supplementary materials}

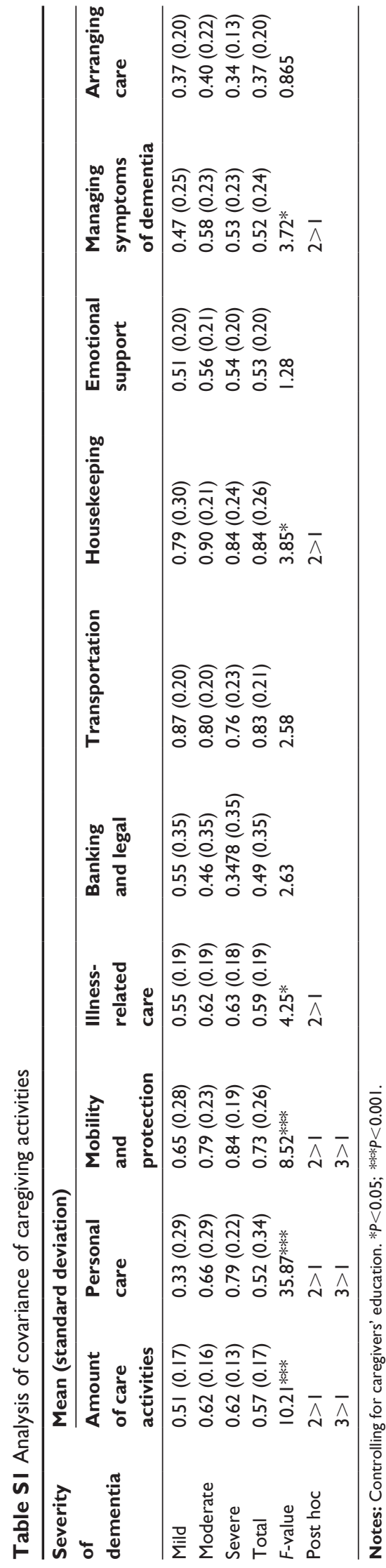

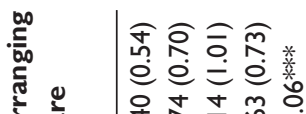

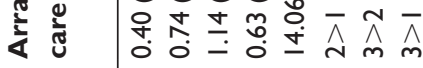

है

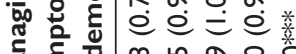

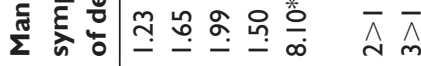

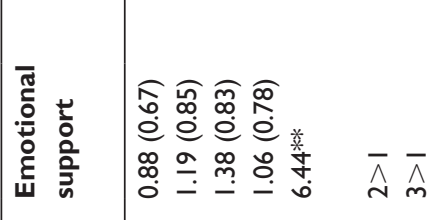

象

สิ์

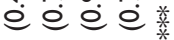

이

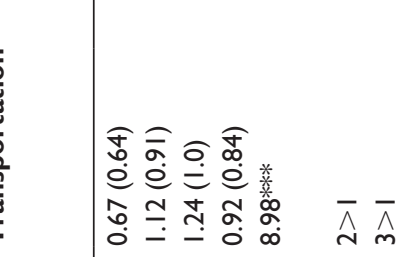

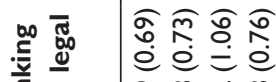

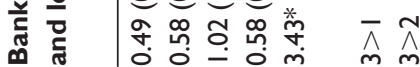

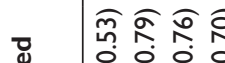

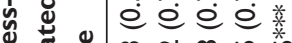

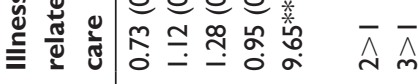

.

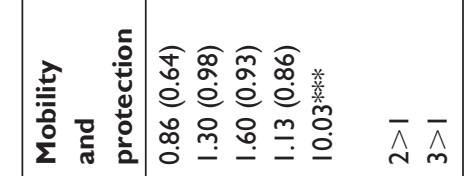

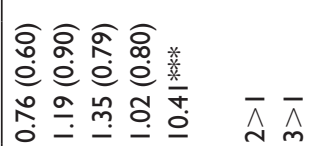

余余余网

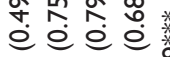

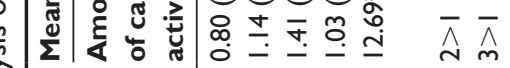

突

กิ

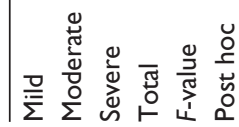




\section{Publish your work in this journal}

Clinical Interventions in Aging is an international, peer-reviewed journal focusing on evidence-based reports on the value or lack thereof of treatments intended to prevent or delay the onset of maladaptive correlates of aging in human beings. This journal is indexed on PubMed Central, MedLine,

CAS, Scopus and the Elsevier Bibliographic databases. The manuscript management system is completely online and includes a very quick and fair peer-review system, which is all easy to use. Visit http://www.dovepress. com/testimonials.php to read real quotes from published authors.

Submit your manuscript here: http://www.dovepress.com/clinical-interventions-in-aging-journal 